\title{
GANGGUAN BERBAHASA PADA ANAK BERKEBUTUHAN KHUSUS DAN IMPLIKASINYA BAGI PEMBELAJARAN BAHASA INDONESIA DI SLB NEGERI 1 PEMALANG
}

\author{
Agustya Dyah Nugrahaeni \\ Pendidikan Bahasa dan Satra Indonesia, Universitas Pancasakti Tegal, Indonesia \\ Email: dyahnugrahaeni@gmail.com \\ Burhan Eko Purwanto \\ Pendidikan Bahasa dan Satra Indonesia, Universitas Pancasakti Tegal, Indonesia \\ Email: burhanekopurwanto58@gmail.com \\ Khusnul Khotimah \\ Pendidikan Bahasa dan Satra Indonesia, Universitas Pancasakti Tegal, Indonesia \\ Email: khusnulups@gmail.com
}

\begin{abstract}
Abstrak
Tujuan penelitian ini adalah Untuk mengetahui jenis gangguan berbahasa pada anak berkebutuhan khusus dan implikasinya bagi pembelajaran Bahasa Indonesia di SLB Negeri 1 Pemalang. Penelitian ini menggunakan pendekatan kualitatif dengan metode deskriptif. Teknik pengumpulan data dengan menggunakan teknik observasi, wawancara dan studi dokumentasi. Teknik analisis data menggunakan tiga teknik yaitu pengklasifikasian, pendeskripsian serta penyimpulan kemudian penyajian hasil analisis yaitu menggunakan metode informal. Hasil penelitian menunjukkan bahwa Jenis gangguan Bahasa yang dialami oleh anak di SLB Negeri 1 Pemalang pada dasarnya mereka adalah anak penyandang disabilitas tunanetra, tunarunguwicara, tunadaksa, dan tunagrahita. Gangguan bahasa pada anak tunanetra terletak pada pemahaman serta perasaan mereka kurang baik dimana bahasa yang digunakan dalam komunkasi harus bisa dinalar. Gangguan bahasa pada anak tunarunguwicara terletak pada pendengaran dan bicaranya sehingga terhambatnya komunikasi lisan/verbal baik secara berbicara ataupun memahami pembicaraan orang lain. Gangguan bahasa pada anak tunadaksa terletak pada kelainan/kerusakan pada otak yang dapat mengakibatkan gangguan gerak, kecerdasan, perilaku, adaptasi, komunikasi, koordinasi, dan persepsi. Gangguan bahasa pada anak tunagrahita terletak pada keterbelakangan intelektual yang disebabkan oleh beberapa faktor terkait yang dapat menyebabkan penderitanya memiliki kecerdasan intelektual di bawah rata-rata, keterbatasan dalam fungsi intelektual yang diantaranya yaitu kecerdasan penalaran, penyelesaian masalah, keterampilan kognitif, dan pembelajaran. Gangguan bahasa pada anak berkebtuhan khusus jika diimplikasikan dalam pembelajaran bahasa Indonesia keduanya saling berkaitan
\end{abstract}

Kata Kunci: Gangguan Berbahasa, Anak Berkebutuhan Khusus, Pembelajaran Bahasa Indonesia.

\begin{abstract}
The purpose of this research is to know the type of language disorder in children with special needs and the implications for learning Bahasa Indonesia in SLB Negeri 1 Pemalang. This study uses a qualitative approach with a descriptive method. Data collection techniques using observation techniques, interviews and documentation studies. Data analysis techniques using three techniques, namely classifying, descriptant and presentation and then presenting the results of analysis is using informal methods. The results showed that the type of language disorder experienced by children in the state SLB 1 Pemalang Basically they are children with impaired disability, Tunarunguwicara, Tunadaksa, and disabled. Language disorder in the blind child lies in the understanding and feeling they lack better where the language used in the communication
\end{abstract}


should be normalable. Language disorders in the child's Tunarunguwicara lies in the hearing and speech so that the abuse of verbal /verbal communication either speak or understand the talks of others. The child's language disorder lies in the abnormalities/damage to the brain that can result in impaired motion, intelligence, behaviour, adaptation, communication, coordination, and perception. The language disorder in children of disabled lies in the intellectual retardation caused by several related factors that can cause the sufferer to have below average intellectual intelligence, limitation in intellectual function such as intelligence reasoning, problem solving, cognitive skills, and learning. Language disorders in children are special when implied in Indonesian language learning are interconnected.

Keywords: Language, disorder, children with special needs, Indonesian language learning.

\section{PENDAHULUAN}

$$
\text { Undang-Undang Republik }
$$

Indonesia Nomor 20 Tahun 2003

tentang Sistem Pendidikan Nasional

pasal 32 menyebutkan bahwa

"Pendidikan Khusus (Pendidikan Luar

Biasa) merupakan pendidikan bagi

peserta didik yang memiliki tingkat

kesulitan dalam mengikuti proses pembelajaran karena kelainan fisik, emosional, mental, social." Undangundang tersebut merupakan landasan bagi anak penyandang disabilitas memeroleh pendidikan Pendidikan adalah suatu proses sosial, yang berfungsi memasyarakatkan peserta didik melalui proses sosialisasi di dalam masyarakat (Hamalik, 2011:73). Penyelenggaraan pendidikan bagi anak penyandang disabilitas dapat dilakukan melalui dua metode/institusi, yaitu Pendidikan Inklusi dan Pendidikan Luar

Biasa. Pendidikan luar biasa dikhususkan untuk anak penyandang disabilitas salah satunya yaitu Sekolah Luar Biasa Negeri 1 Pemalang. Adapun klasifikasi anak penyandang disabilitas meliputi kelainan indra penglihatan (tunanetra), kelainan indra pendengaran (tunarungu), kelainan kemampuan berbicara (tunawicara), kelainan fungsi anggota tubuh (tunadaksa), anak yang memiliki kemampuan mental sangat rendah (tunagrahita), kelainan dalam aspek sosial (tunalaras). (Efendi, 2008:2-3).

Bahasa merupakan komponen utama dalam berkomunikasi selain gerak tubuh, nada, dan sebagainya. Pada intinya bahasa adalah tanda dan simbol yang mewakili sesuatu yang diungkapkan, baik lisan maupun tulisan (Swarniti \& Yuniari, 2019). Ada beberapa pandangan yang menyatakan bahwa Bahasa merupakan hasil dari perilaku stimulus-respons, setiap perilaku di dalam Bahasa merupakan akibat adanya stimulus, dengan demikian apabila peserta didik hendak memperoleh ujaran, peserta didik harus memperbanyak penerimaan stimulus. Rangsangan yang berupa perilaku berbahasa orang lain merupakan sumber proses aktivitas berbahasa peserta didik (Iskandarwassid \& Dadang, 2007:87). Proses tersebut bersifat sangat kompleks dikarena mensyaratkan berfungsinya berbagai organ tubuh yang 
dapat mempengaruhi mekanisme berbicara, berpikir, atau mengolah pikiran ke dalam bentuk kata-kata dan kalimat, serta modalitas mental yang terungkap saat berbicara yang juga ditentukan oleh faktor lingkungan, alat bicara dan fungsi otak yang baik akan mempengaruhi memperoleh bahasa yang baik. Tetapi berbeda dengan anak yang memiliki penyandang disabilitas tentu akan mengalami kesulitan dalam berbahasa atau mengalami gangguan berbahasa.

Gangguan berbahasa adalah sebuah halangan, rintangan, dan sesuatu yang menyebabkan ketidaklancaran orang dalam mengucapkan bunyi artikulasi atau kata untuk mengekspresikan, mengatakan, serta menyampaikan pikiran, gagasan, dan perasaan. Salah satu gangguan berbahasa adalah anak penyandang disabilitas yang mana anak tersebut mengalami kesulitan untuk berkomunikasi, keterlambatan bahasa, dan proses berpikir lamban. Dalam hal ini anak penyandang disabilitas hanya dapat mengikuti proses belajar di sekolah luar biasa.

Terdapat banyak mata pelajaran yang diajarkan pada pendidikan luar biasa yang sama dengan pendidikan pada umumnya, tak terkecuali mata pelajaran bahasa Indonesia. Mata pelajaran tersebut merupakan mata pelajaran yang menekankan pada aspek belajar pada berkomunkasi (Daroni,
2018:276). Selain itu, pelajaran bahasa Indonesia adalah mata pelajaran yang memberikan pengajaran membaca, menulis, mengarang, membaca, mendikte, bebicara atau bercerita. Dengan adanya pembelajaran bahasa Indoesia di sekolah maka peserta didik akan terlatih untuk selalu menggunakan bahasa Indonesia yang baik, benar sesuai dengan ejaan selain itu peserta didik dapat berlatih untuk mengungkapkan pikiran serta perasaan ke dalam bentuk tulisan/lisan.

Berdasarkan hasil wawancara dengan narasumber yang dilakukan sebelum penelitian menunjukan bahwa terdapat berbagai permasalahan antara kelas tunanetra, tunarunguwicara, tunadaksa dan tunagrahita. Permasalahan yang terdapat di kelas tunadaksa \& tunarunguwicara antara lain adalah sebagian siswa dengan kondisi normal (bisa mengikuti pebelajaran) dan sebagain siswa dengan kondisi memiliki kemampuan kurang. Untuk kelas tunanetra permasalahan yang ada adalah pada penglihatannya yang dimana harus menggunakan huruf Braille, dan untuk kelas tunagrahita yaitu adanya keterbatasan inteligensi yang dapat diartikan bahwa kemampuan untuk mempelajari informasi serta keterampilan menyesuaikan diri dengan masalah dan situasi kehidupan baru, cara berpikir abstrak. Selain itu mengalami kesulitan kurang terampil dalam berkomunikasi dan kemampuan belajarnya cenderung belajar dengan membeo atau 
meniru saja perkataan orang lain. Menurut keterangan guru untuk kelas tunadaksa, tunarunguwicara dan tunagrahita dalam proses pembelajaran anak tersebut sebagian memiliki tingkat kebosanan serta mengalami gangguan berbahasa saat berkomunikasi pada waktu pembelajaran berlangsung. Oleh karena itu, peneliti tertarik untuk melakukan penelitian terhadap Gangguan Berbahasa dan Implikasinya bagi Pembelajaran Bahasa Indonesia, melihat dari data yang ada, maka peneliti melakukan penelitian tentang "Gangguan Berbahasa pada Anak Berkebutuhan Khusus dan Implikasinya bagi Pembelajaran Bahasa Indonesia di SLB Negeri 1 Pemalang". Penelitian ini akan menggambarkan jenis gangguan berbahasa yang dialami, perkembangan dan penggunaan bahasa, serta upaya/metode yang digunakan oleh guru dalam proses pembelajaran.

\section{METODE}

Metode yang digunakan dalam penelitian ini adalah deskriptif kualitatif (Santika, 2020;29). Gaya penelitian kualitatif berusaha mengkonstruksi realitas dan memahami maknanya (Santika, 2019:984). Dalam metode deskriptif kualitatif, peneliti mendeskripsikan hasil wawancara terhadap guru untuk memperoleh data penelitian. Wujud data dalam penelitian adalah hasil peserta didik selama mengikuti kegiatan pembelajaran di sekolah yang diperoleh peneliti melalui wawancara yang berupa kartu data, dan dokumentasi. Penyajian hasil analisis yang digunakan dalam penelitian adalah metode informal dimana data yang disajikan dalam deskripsi khas verbal dengan rumusan kata-kata biasa tanpa menggunakan lambang.

\section{HASIL PEMBAHASAN}

Penelitian ini dilaksanakan di SLB Negeri 1 Pemalang Jl. Dr. Cipto Mangkusumo 3A Kabupaten Pemalang, Jawa Tengah. Penelitian dilakukan dengan menggunakan teknik wawancara secara langsung dan melalui media sosial (Handphone) Pengambilan data tersebut peneliti mewawancarai dua narasumber di SLB Negeri 1 Pemalang, narasumber yang diwawancarai adalah guru mata pelajaran Bahasa Indonesia dan guru mata pelajaran Bahasa Inggris di SLB Negeri 1 Pemalang.

1. Gangguan apa saja yang dialami oleh anak penyandang disabilitas?

\section{a. Informan 1:}

"Untuk kelas tunagrahita Gangguan bahasa yang dialami oleh anak kelas c yaitu sulit memahami bahasa-bahasa kongkrit karena susah untuk mengucapkan konsonankonsonan yang doble. Apabila ditanya terkadang siswa tidak memahami pertanyaan tersebut."

Contohnya :

Guru : "siapa nama ayah kamu?"

Siswa : "dido"

Dengan pertanyaan sederhana tersebut siswa bisa menjawabnya dibandingkan dengan pertanyaan

Guru : "siapa nama lengkap ayah mu ?"

"Siswa akan merasa kesulitan untuk menjawabnya karena daya ingat dan kosa 
kata yang diperoleh kurang. Sedangkan untuk kelas yang terdiri atas penyandang disabilitas (tunarunguwicara \& tunadaksa) sebagian siswa tidak ada masalah dan bisa mengikuti pembelajaran saat guru memberikan materi sedangkan sebagian siswa menggunakan bahasa isyarat. Informan menjawab.”

\section{b. Informan 2:}

"Untuk kelas tunanetra low vision hampir sama dengan peserta didik normal sedangkan untuk tunanetra total blind kurang sedikit konsentrasi misalnya saat pembelajaran berlangsung terdengar suarasuara bising yang mengganggu, daya serap tunanetra total blind biasanya harus diulang beberapa kali materi atau kosa kata yang diajarkan agar benar-benar memahami dan dimengerti oleh siswa. Untuk kelas tunagrahita tingkat kemampuannya berbedabeda, media dalam pembelajaran tunagrahita lebih cenderung ke visualnya seperti gambar atau lagu-lagu. Untuk tunadaksa tidak ada masalah IQ normal hanya akses mobilitasnya yang mengalami kesulitan. Di kelas C terdapat siswa Down Syndrom yang tingkat pemahamannya di bawah tingkat grahita, mereka hanya bisa menyalin dan mengalami kesulitan dalam berkomunikasi.

Dari penjelasan informan di atas disimpulkan bahwa gangguan bahasa atau perkembangan bahasa pada siswa disebabkan oleh mental intelektual, disfungsi minimal otak selain itu mengalami keterlambatan dalam kemampuan berbahasa yang dapat terjadi pada fonologis, semantik, dan sinatksis sehingga kesulitan dalam menerima respon dari orang lain saat berkomunikasi.

2. Bagaimana perkembangan bahasa pada anak penyandang disabilitas?

\section{a. Informan 1:}

"Perkembangan bahasa pada kelas grahita sedikit lamban dalam pengetahuannya, jika secara umum untuk anak kelas grahita bisa memahami dan tidak menggunakan bahasa intelek. Dalam pembelajaran di kelas grahita guru lebih menggunakan media gambar dari pada tulisan karena siswa lebih mudah memahami materi yang diberikan oleh guru misalnya saat guru menunjukkan media gambar $\mathrm{Hp}$ siswa mampu memahami maksud dari gambar tersebut, selain media gambar guru lebih sering mendongeng atau bercerita. Sedangkan Perkembangan bahasa pada kelas tunadaksa \& tunarunguwicara mengalami kesulitan berbahasa umum dan dimana siswanya dalam berkomunikasi menggunakan bahasa insyarat."

\section{b. Informan 2:}

"Untuk tunanetra perkembangan bahasa bisa diikuti dengan baik dan daya serapnya juga baik. Untuk kelas grahita Down Syndrom mereka mengalami kesulitan dalam berkomunikasi karena penguasaan kosa katanya yang sangat terbatas dan hanya bisa menggunakan bahasa isyarat selain itu harus diulng-ulang saat memberikan materi atau kosa kata hal ini untuk mendorong siswa agar pemahan kosa kata lebih banyak. Untuk kelas tunadaksa tidak ada masalah seperti anak normal. Sedangkan untuk anak kelas tunarunguwicara mengalami kesulitan 
dalam berbahasa umum saat berkomunikasi."

Dari penjelasan informan di atas dapat disimpulkan bahwa gangguan bahasa siswa mengalami kesulitan dalam meniru pengulangan bunyi-bunyi bahasa selain itu kerusakan pada fasicullus arcuatus serta dibagian dalam gyrus supramarginal di lobus temporalis superior.

3. Usaha apa yang dilakukan guru untuk mengatasi gangguan berbahasa pada anak?

\section{a. Informan 1:}

"Anak yang memiliki gangguan berbahasa atau kemampuan berbahasanya kurang biasanya siswa diajak untuk sering berkomunikasi sehingga siswa merasa nyaman dan dapat memberikan respon kepada guru yang sedang berkomunikasi dengan mereka."

\section{b. Informan 2:}

"Usaha untuk mengatasi gagguan berbahasa dengan menerapkan media yang berbeda-beda utuk masing-masing anak tunanetra. Misal terdapat dua karakter yang berbeda untuk tunanetra low visio menggunakan media yag diperbesar sedangkan untuk tunanetra total blind menggunakan bantuan huruf Braille dengan media tersebut guna merangsang siswa untuk memahami materi yang diberikan guru, misalnya siswa diminta untuk mencari informasi atau kosa kata. Contohnya Get $U p$ yang ditulis dalam bentuk Braille. Sedangkan untuk tunanetra low blind dengan huruf yang diperbesar, siswa diminta untuk mencai tahu artinya mereka dirangsang agar lebih aktif dan apabila siswa mengalami kesulitan dalam mencari tahu kosa kata ssiwa bisa menanyakannya ke guru atau mencari tahu melalui goggle translit. Untuk anak tunagrahita Down syndrom lebih banyak pembelajaran ke arah visualnya seperti animasi dan lagu-lagu.

Dari penjelasan informan di atas dapat disimpulkan bahwa gangguan bahasa disebabkan oleh adanya kerusakan pada pusat-pusat bahasa sehingga siswa mengalami kehilangan kemampuan dalam simbolisasi

\subsection{Gangguan Berbahasa}

Jenis gangguan Bahasa yang dialami oleh anak di SLB Negeri 1 Pemalang pada dasarnya mereka adalah anak penyandang disabilitas tunanetra, tunarunguwicara, tunadaksa, dan tunagrahita. Tunanetra yaitu anak yang mengalami kekurangan pada penglihatannya atau indera penglihatannya sudah tidak berfungsi. Anak penyandang disabilitas penglihatan dalam memperoleh angka dan kosakata hampir sama dengan anak normal bedanya dalam hal pemahaman serta perasaan mereka kurang baik, kosa kata untuk penyandang disabilitas penglihatan/tunanetra lebih cenderung katakata yang sudah pasti/definitive. Gangguan atau hambatan bahasa pada anak penyandang disabilitas penglihatan/tunanetra adalah dimana bahasa yang digunakan dalam komunkasi harus bisa dinalar oleh mereka sehingga tahapanya melalui proses penalaran dalam berkomunikasi sangat bervariasi. Tunarunguwicara yaitu anak yang memiliki 
kekurangan dari segi pendengaran dan kemampuan wicaranya atau bicaranya sejak lahir/usia dini (tuli prabahasa) dengan kurang baik sehingga mengalami gangguan berbahasa dalam memproses dan menerima informasi saat komunikasi. Dampak dari ketunarungua ialah terhambatnya komunikasi lisan/verbal baik secara berbicara ataupun memahami pembicaraan orang lain, selain itu ketunarunguan dapat mengakibatkan perkembangan kemampuan memahami lambang atau berbahasa artinya anak tidak mengenal lambang/kode (nama) benda, suatu kegiatan serta perasaan pada anak tidak memahami aturan sistem tata Bahasa.

Tunadaksa yaitu anak yang memliki kekurangan atau kelainan pada anggota tubuhnya yang meliputi alat gerak seperti otot, tulang ataupun persendian yang mengakibatkan gangguan untuk berkomunikasi, adaptasi, mengkoordinasi, dan mobilitas. Jika dilihat secara umum anak penyandang tunadaksa mengalami kelainan/kerusakan pada otak yang dapat mengakibatkan gangguan gerak, kecerdasan, perilaku, adaptasi, komunikasi, koordinasi, dan persepsi sehingga mereka mengalami gangguan berbahasa atau lamban dalam menerima respon orang lain saat berkomunikasi. Selain itu dapat dilihat dari tingkat kecerdaasan anak penyandang tunadaksa sebagian besar mengalami kesulitan dalam belajar dan perkembangan kognitif. Hambatan berbahasa pada anak penyandang tunadaksa perkembangan bahasanya tidak begitu normal sehingga kesulitan dalam berartikulasi, respirai ataupun phonasi.

Tunagrahita yaitu anak yang memiliki keterbelakangan intelektual yang disebabkan oleh beberapa faktor terkait yang dapat menyebabkan penderitanya memiliki kecerdasan intelektual di bawah rata-rata, keterbatasan dalam fungsi intelektual yang diantaranya yaitu kecerdasan penalaran, penyelesaian masalah, keterampilan kognitif, dan pembelajaran. Untuk anak kelas tunagrahita di SLB Negeri 1 Pemalang terdapat tunagrahita type Down Syndrome. Down Syndrome adalah anak yang mempunyai kelainan genetik dan menyebabkan penderitanya memiliki tingkat kecerdasan yang sangat rendah. Anak penyandaang disabilitas Down Syndrome mengalami keterlambatan pada perkembangan kognitifnya, perkembangan motorik halus serta berbicara, perkembangan motorik kasar yang sangat lambat. Namun perkembangan kognitif pada mereka berbeda-beda dan sangat bervariasi.

Anak penyandang disabilitas Down Syndrome memiliki gangguan atau hambatan dalam berbahasa serta ucapan saat berkomunikasi, mereka mengalami kesulitan dalam memahami tata bahasa atau struktur bahasa serta memproduksi suara. Permasalahan utama yang dialami anak penyandang disabilitas Down Syndrome adalah terletak pada perkembangan morfologi dan sintaksisnya mereka mengalami kesulitan dalam semantik dimana terbatas dalam penggunaan dan pemahaman berkosa kata. 
Pada dasarnya anak penyandang disabilitas tunagrahita memiliki gangguan berbahasa lebih banyak dibandingkan dengan anak penyandang disabilitas lainnya, mereka cenderung tidak dapat menggunakan kalimat-kalimat majemuk dan hanya dapat menggunakan kalimat-kalimat tunggal, mereka juga mengalami kesulitan dalam menguasai gramatikal. Dalam hal semantik anak penyandang disabilitas tunagrahita cenderung mengalami kesulitan dalam menggunakan sinonim, penggunaan kata sifat, dan kata benda. Sedangkan dalam hal penggunaan kalimat tunggal anak penyandang disabilitas mengalami gangguan pada artikulasi, mengalami kelambatan dalam berbicara. Bunyi bahasa pada anak penyandang disabilitas tunagrahita cenderung mengalami gangguan artikulasi yang menunjukkan kesulitan pada aspek fonologis yang berkaitan dengan perkembangan merabanya serta juga diakibatkan keterlambatan perkembangan berbahasa. Gangguan semantik pada anak penyandang disabilitas adalah tentang penggunaan kata benda, mereka lebih menggunakan kata dasarnya (contohnya motor, sapi) tidak mencapai subordinatnya (contohnya Rally, kambing) atau tingkat superordinat (contohnya kendaraan, binatang), objek tersebut dipilih karena kelompok dasarnya misalnya mereka tidak mempertimbangkan motor gede, motor vespa mereka akan menyebutnya sebagai motor, mereka akan kesulitan jika harus menyebut hingga subordinat dan superordinat.
Tata bahasa awal pada anak penyandang disabilitas tunagrahita sangat terlambat dibandingkan dengan anak normal, anak penyandang tunagrahita type Down Syndrome diusia enam tahun mereka hanya mampu merangkai dua kata menjadi ungkapan yang bermakna sedangkan mereka yang berusia empat tahun belum mampu menyusun ucapan dari dua kata. Gangguan pragmatik pada anak penyanang disabilitas tunagrahita adalah apabila dari mereka sedang diajak berkomunikasi seringkali beralih topik pembicaraan, mereka akan mengalami kesulitan untuk berbicara sesuai dengan tapik karena kemampuan pragmatis pada mereka sangat rendah. Jadi anak penyandang disabilitas tunagrahita mempunyai kesulitan/hambatan dalam berfikir dan bernalar, akibat hambatan tersebut mereka mengalami kelemahan dalam proses belajar dan beradaptasi dengan lingkungan sekitar. Kesulitan/hambatan belajar anak penyandang disabilitas tunagrahita meliputi kesulitan membaca, menulis, dan menghitung.

\subsection{Implikasi dalam Pembelajaran}

\section{Bahasa Indonesia di SLB Negeri 1}

\section{Pemalang}

Gangguan bahasa pada anak berkebtuhan khusus jika diimplikasikan dalam pembelajaran bahasa Indonesia keduanya saling berkaitan karena dalam pembelajaran bahasa Indonesia terdapat pembelajaran tata bahasa serta struktur bahasa dimana peseta didik penyandang disabilitas dapat memperolehnya dengan baik sehingga pemerolehan bahasa pada 
mereka meningkat. Proses pembelajaran Bahasa Indonesia di SLB Negeri 1 Pemalang disesuaikan dengan kebutuhan peserta didik dan karakter khusus sehingga pembelajaran anak penyandang disabilitas satu dengan yang lain berbeda. Saat proses pembelajaran berlangsung dalam menyampaikan materi guru harus memperhatikan perbedaan kebutuhan yang dimiliki oleh peserta didik. Selain itu juga harus memperhtikan karakteristik pada mereka bahwa anak yang memiliki berkebutuhan khusus mengalami gangguan atau hambatan dari segi kognitif, daya ingat, persepsi, penalaran, mengembangkan ide serta evaluasi. Berdasarkan karakteristik tersebut mereka cenderung mudah melupakan materi yang disampaikan oleh guru sehingga guru pada saat menjelaskan materi yang sama harus dengan diulangulang.

Dapat diketahui gangguan-gangguan berbahasa pada anak penyandang disabilitas pembelajaran bahasa Indonesia di sekolah sangat berpengaruh untuk mereka dapat meningkatkan pemerolehan bahasa yang baik. Pelaksaan pembelajaran bahasa Indonesia di SLB Negeri 1 Pemalang mengajarkan peserta didik dalam hal segi membaca, menulis, dan berhitung. Agar dapat belajar membaca perserta didik harus menguasai atau dapat berbicara serta memahami bahasa yang sederhana, didalam sebuah percakapan akan terjadilah sebuah proses pendengarkan, melihat dan gerakan. Untuk melatih peserta didik permulaan memperoleh bahasa atau membaca adalah belajar melihat dan mendengarkan dengan baik. Untuk mendukung hal tersebut guru mempunyai peranan besar dalam pembelajaran di sekolah.

\section{PENUTUP}

\section{Simpulan}

Gangguan bahasa pada anak tunanetra adalah terletak pada pemahaman serta perasaan mereka kurang baik. dimana bahasa yang digunakan dalam komunkasi harus bisa dinalar. Gangguan bahasa pada anak tunarunguwicara adalah terletak pada pendengaran dan bicaranya sehingga terhambatnya komunikasi lisan/verbal baik secara berbicara ataupun memahami pembicaraan orang lain. Gangguan bahasa pada anak tunadaksa adalah terletak pada kelainan/kerusakan pada otak yang dapat mengakibatkan gangguan gerak, kecerdasan, perilaku, adaptasi, komunikasi, koordinasi, dan persepsi. Gangguan bahasa pada anak tunagrahita adalah terletak pada keterbelakangan intelektual yang disebabkan oleh beberapa faktor terkait yang dapat menyebabkan penderitanya memiliki kecerdasan intelektual di bawah rata-rata, keterbatasan dalam fungsi intelektual yang diantaranya yaitu kecerdasan penalaran, penyelesaian masalah, keterampilan kognitif, dan pembelajaran Gangguan bahasa pada anak berkebtuhan khusus jika diimplikasikan dalam pembelajaran bahasa Indonesia keduanya saling berkaitan.

\section{DAFTAR PUSTAKA}

Creswell, John W (2017). Research Desighn: Pendekatan Metode 
Kualitatif, Kuantitatif dan Campuran. Yogyakarta: Pustaka Pelajar.

Daroni, Gangsor Ali (2018). "Pembelajaran Bahasa Indonesia untuk Anak Autis." Universitas Sebelas Maret. Jurnal Pendidikan Bahasa dan Sastra. 2,271-290.

Departemen Sosial RI. Panduan Kriteria Penyandang Cacat Fisik, (Jakarta: Direktorat Pelayanan dan Rehabilitas Sosial, Direktorat Sosial $\mathrm{RI}, 2006)$.

Efendi, Mohammad (2008). Pengantar Psikopedagogik Anak Berkelainan. Jakarta: PT Bumi Aksara

Hamalik, Oemar (2011). Dasar-Dasar Pengembangan Kurikulum. Bandung: PT Remaja Rosdakarya.

Indah, Rohmani Nur (2017). "Gangguan Berbahasa Kajian Pengantar”. Malang: Uin-Maliki Press.

Iskandarwassid \& Dadang (2013). Strategi Pembelajaran Bahasa. Bandung: PT Remaja Rosdakarya

Martina, (2014). "Hambatan Berbahasa Anak Berkebutuhan Khusus di Bina Anak Bangsa Pontianak”. Balai Bahasa Provinsi Kalimantan Barat. Jurnal badan bahasa kemendikbud. Vol 10 No. 1 hal.28-40.

Pujaningsih, (2010). "Perkembangan Bahasa dan Gangguan Bahasa pada Anak Berkebutuhan Khusus". Universitas Negeri Yogyakarta. Jurnal Pendidikan Khusus. Vol. 6 No. 1.

Rakhmanita, Elza (2020). "Kajian Psikolinguistik Terhadap Gangguan Berbahasa Autis". Universitas Sebelas Maret. Jurnal Pendidikan Bahasa dan Sastra.

Riyadin Agung dkk, (2017). "Karakteristik Anak Berkebutuhan Khusus di
Sekolah Dasar Negeri (INKLUSI) di Kota Palangka Raya." Anterior Jurnal. Pendidikan Guru Sekolah Dasar. Universitas Muhammadiyan Palangkaraya. Vol 17 Issue 1, Desember 2017, page 22-27.

Santika, I. G. N. (2020). Menelisik Akar Kegaduhan Bangsa Indonesia Pasca Disetujuinya Hasil Revisi UU KPK Dalam Perspektif Pancasila. Jurnal Ilmiah Ilmu Sosial. 6 (1), 6-36. DOI: http://dx.doi.org/10.23887/jiis.v6i1.2 $\underline{5001}$

Santika, I. G. N., Rindawan, I. K., \& Sujana, I. G. (2019). Memperkuat Pancasila Melalui Pergub No. 79 Tahun 2018 Dalam Menanggulangi Pengikisan Budaya Di Era Revolusi Industri 4.0. Prosiding Seminar Nasional Inobali 2019, 79, 981-990

Subana \& Sunarti, (2009). Strategi Belajar Mengajar Bahasa Indonesia: Berbagai Pendekatan, Metode Teknk, dan Media Pengajaran. Bandung: Pustaka Setia.

Sudaryanto, (2008). Metode dan Analisis Bahasa: Pengantar Bahasa kebudayaan secara Linguistis. Yogyakarta: Duta Wahana Perss.

Surya, Muhammad (1996). Psikologi Pembelajaran dan Pengajaran. Bandung: FIP IKIP Bandung.

Sutatminingsih, R (2002). Pengaruh Terapi Rehabilitas Secara Kelompok terhadap Peningkatan Konsep Diri Pada Penyandang Disabilitas Fisik Usia Dewasa Awal. Tesis S2. Yogyakarta: Universitas Gajah Mada. Diakses pada tanggal 22 Februari 2020.

Suyitno, (2018). Metode Penelitian Kualitatif. Tulungagung: Akademia Pustaka.

Swarniti, N. W., \& Yuniari, N. M. (2019). Keberadaan Leksikon Pohon Langka di Denpasar: Studi Ekolinguistik. 


\begin{abstract}
Seminar Nasional INOBALI 2019 Inovasi Baru Dalam Penelitian Sains, Teknologi Dan Humaniora, 405-411. https://eproceeding.undwi.ac.id/index. php/inobali/article/view/180
\end{abstract}

Syah, Muhibbin (2015). Psikologi Belajar. Jakarta: Rajawali Press.

\title{
Sumber lainnya
}

Undang-Undang Nomor 20 Tahun 2003 tentang Sistem Pendidikan Nasional. Jakarta.

Undang-Undang Nomor 20 Pasal 32 Tahun 2003 teentang Pendidikan Khusus (Pendidikan Luar Biasa). Jakarta.

Undang-Undang Nomor 8 Tahun 2016 tentang Penyandang Disabilitas. Jakarta 